\title{
The effect of matrix toughness and loading rate on the mode-II interlaminar fracture toughness of glass-fibre/vinyl-ester composites
}

\author{
P. Compston ${ }^{\text {a,*}}$, P.-Y.B. Jar ${ }^{\text {a,1, }}$, P.J. Burchill ${ }^{\text {b }}$, K. Takahashi ${ }^{\mathrm{c}}$ \\ ${ }^{a}$ Department of Engineering, Faculty of Engineering and Information Technology, The Australian National University, Canberra ACT 0200, Australia \\ ${ }^{\mathrm{b}}$ Department of Defence, DSTO, Aeronautical and Maritime Research Laboratory, PO Box 4331, Melbourne, Victoria 3001, Australia \\ ${ }^{\mathrm{c}}$ Research Institute for Applied Mechanics, Kyushu University, Kasuga, Fukuoka 816-8580, Japan
}

Received 14 January 2000; received in revised form 19 June 2000; accepted 19 October 2000

\begin{abstract}
Glass-fibre-reinforced composites are increasingly used for structural applications. However, like high-performance carbon-fibre composites, they are susceptible to mode-II-dominated delamination. In response to this problem, this paper investigates the effect of matrix toughness and loading rate on the mode-II interlaminar fracture toughness $\left(G_{\text {IIc }}\right)$ of unidirectional glass-fibre composites with brittle and rubber-toughened vinyl ester matrices. Mode II tests were conducted $\sigma$ n end-notch-flexure (ENF) specimens at test rates ranging from $1 \mathrm{~mm} / \mathrm{min}$ to $3 \mathrm{~m} / \mathrm{s}$. The $G_{\text {IIc }}$ results were compared to the order of matrix $G_{\text {Ic }}$. There was no significant effect of loading rate or matrix toughness on $G_{\mathrm{IIc}}$. The absence of a loading rate effect is consistent with the bulk of the experimental data in the literature, but the absence of a matrix effect is not. Microscopic examination of fracture surfaces shows similar matrix deformation in each composite. The through-thickness matrix deformation zone size is also similar. These observations suggest similar energy absorption in each composite and hence support the $G_{\text {IIc }}$ test results. It is concluded that failure is interface controlled, whereby unstable fracture is initiated after a similarly short period of crack growth in each composite, and before an increase in $G_{\text {IIc }}$ as a result of increased matrix toughness becomes apparent. The $G_{\text {IIc }}$ results indicate that the use of rubber-toughened vinyl ester matrices in glass-fibre composites will not improve resistance to impact-induced mode II-delamination. However, through-thickness impact damage in composite structures is likely to result from mixed-mode (I/II) loading. Therefore, suggestions for future work include investigation of the matrix effect on mixed-mode (I/II) interlaminar fracture toughness, and on delamination resistance of plate structures subjected to transverse low-velocity impact. (C) 2001 Elsevier Science Ltd. All rights reserved.
\end{abstract}

Keywords: A. Polymer-matrix composites; B. Fracture toughness; C. Delamination; C. Deformation; Mode II

\section{Introduction}

Delamination is one of the major failure modes in composite structures subject to low-velocity transverse impact loading. Initial damage is usually in the form of shear matrix cracks in layers close to the point of impact, or tensile matrix cracks in back-face layers where bending introduces high tensile stresses [1-3]. These matrix cracks then initiate delamination. The

\footnotetext{
* Corresponding author at current address: Materials Science and Engineering, Department of Engineering, The University of Liverpool, Liverpool L69 3GH, UK. Tel.: +44-151-794-5381; fax: +44-151-7944675 .

E-mail address: p.compston@liverpool.ac.uk (P. Compston).

${ }^{1}$ Current address: Department of Mechanical Engineering, University of Alberta, Edmonton, Alberta, Canada, T6G 2G8.
}

presence of delaminations within the composite structure will adversely affect structural integrity, with compressive strength and fatigue performance most seriously affected $[1,4,5]$.

Since impact-induced delamination is mode II dominated $[1,6]$, high rate test mode-II interlaminar fracture tests have been conducted to gain insight into the failure process and potential toughening mechanisms. Stitched and knitted fibre architectures, which will provide some through-thickness reinforcement, can improve resistance to impact-induced delamination [7,8]. However, the stitching process can cause localised damage, and the overall fibre architecture produces resin-rich pockets, reduced volume fraction and high stress concentrations, all of which can reduce structural performance [9]. Alternatively, tougher matrices can be used to increase dynamic mode II-interlaminar fracture toughness $G_{\text {IIc }}$ of 
fibre-reinforced composites. Smiley and Pipes [10], Friedrich et al. [11], Maikuma et al. [12] and Blackman et al. [13] have all reported higher $G_{\text {IIc }}$ for tough PEEKmatrix/carbon-fibre composites than for the brittle epoxy-matrix counterparts. Similar conclusions were made by Compston et al. [14] for glass-fibre composites with a range of brittle thermoset matrices.

In a practical situation, the rate at which the composite structure is impacted is unpredictable. Therefore, the effect of a variation in loading rate on mode-II delamination resistance is also important. The aforementioned studies [10-14], used to highlight the matrix effect, show a decrease in $G_{\text {IIc }}$ with increased loading rate. However, Cantwell [15] has reported an increase in $G_{\text {IIc }}$ for carbon-fibre/PEEK with increased loading rate, as have Todo et al. [16] for a carbon-fibre/polyamide- 6 composite. However, Todo et al. also reported a decrease of $G_{\text {IIc }}$ with increasing loading rate when the same polyamide- 6 matrix was reinforced with glass-fibre composites. Through fracture surface examination, Todo et al. attributed the different $G_{\text {IIc }}$ trend to variation in failure mode, with interfacial failure more dominant in the glass-fibre composite and cohesive matrix failure more dominant in carbon-fibre composite. It is clear, therefore, that discrepancies in the effect of loading rate exist. This point was made by Cantwell and Blyton [17] in a more extensive review of loadingrate effects on composite $G_{\text {IIc }}$. However, Cantwell and Blyton also concluded that the bulk of published experimental data shows no significant reduction in $G_{\text {IIc }}$ as a result of increased loading rate.

Although mode II work on glass-fibre composites has been cited here, the bulk of the high rate mode II testing has been conducted on high-performance carbon-fibre reinforced composites. However, lower-cost glass-fibrereinforced composites are increasingly used for structural applications. As discussed by Davies [18], one of the greatest areas of potential for application of glassfibre composites is in a marine environment (for examples, see Refs. [19,20]). Applications include civil and military surface vessels, offshore structures and underwater structures. Ageing in corrosive marine environments and delamination as a result of wave impact or shock loading are among the problems that have to be addressed for these composites [18]. In this respect, vinyl ester resin is attractive for use as a composite matrix. It has shown greater resistance to hydrolysis [21] and greater retention of mechanical properties after accelerated ageing tests compared to more commonly used polyester resins [22]. Furthermore, the toughness of commercial vinyl esters can be significantly enhanced by the addition of relatively small amounts of liquid rubber $[23,24]$.

Previous work has shown that, compared to the use of brittle vinyl esters, rubber-modified vinyl-ester matrices improve significantly the mode I interlaminar fracture toughness of its glass-fibre composites at static and dynamic loading rates [25-27]. In response to the susceptibility of fibre-reinforced composites to impactinduced mode II delamination, this paper investigates the influence of matrix toughness and loading rate on $G_{\text {IIc }}$ for the same glass-fibre/vinyl-ester composites.

\section{Experimental}

\subsection{Materials}

Commercial unidirectional E-glass fibre (Owens Corning R25H), with silane sizing and fibre areal weight $300 \mathrm{~g} / \mathrm{m}^{2}$, were used as the reinforcement. Five vinylester resins were used as matrices. Two were commercial vinyl esters (Dow Chemical Co.): Derakane 411-45 a bisphenol A epoxy-based vinyl-ester resin, and Derakane 8084 a toughened version of 411-45 modified with a reactive acrylonitrile/butadiene copolymer during manufacture. The three other matrices were rubbermodified. Derakane 8084 and Hetron 922 (Huntsman Chemical Co.), which is equivalent to Derakane 411-45, were used as the base resins. Hetron 922 was modified with a core/shell rubber additive (EXL2602, Rohm and Haas). The 8084 resin was modified with BF Goodrich liquid rubber additives: a vinyl terminated acrylonitrile/ butadiene copolymer (VTBN X33) and a carboxy-terminated acrylonitrile/butadiene copolymer prereacted with an aliphatic oligomeric epoxide (CTBN S22) [28]. The toughened matrices, with additive wt. $\%$, are summarised in Table 1. Further details on the formulation of these matrices are available elsewhere [25].

Composite laminates were made for each matrix by hand lay-up in an open mould, then evacuated using the vacuum bag technique. Each laminate contained 24

Table 1

Summary of rubber-modified matrices

\begin{tabular}{lllll}
\hline Matrix & Base resin & Additive & & \\
\cline { 3 - 5 } & & Type & Reference & Supplier \\
\hline 9EXL & Hetron 922 & Core-shell rubber & EXL2602 & Rohm and Haas \\
8 XX33 & Derakane 8084 & Liquid rubber & VTBNX33 & BF Goodrich \\
8S22 & Derakane 8084 & Liquid rubber & CTBNS22 & BF Goodrich \\
\hline
\end{tabular}


fibre plies and for each ply the fibre:resin mass ratio was 1:1. A $15 \mu \mathrm{m}$ thick aluminium film, inserted at midthickness, acted as an artificial starter crack in the test specimens subsequently cut from the laminate. The film was coated with a water-based PTFE release agent (Safelease \#30, Airtech Inc.) prior to insertion. After an initial room temperature cure, the laminates were postcured at $90^{\circ} \mathrm{C}$ for $4 \mathrm{~h}$.

Composite fibre volume fraction was estimated from the equation [29]:

$V_{\mathrm{f}}=\frac{F A W \cdot N}{F D \cdot 2 h}$

where $F A W$ is fibre areal weight, $N$ number of plies, $F D$ fibre density $\left(2.56 \mathrm{~g} / \mathrm{cm}^{3}[30]\right)$ and $2 h$ average thickness of at least five specimens cut from the laminate. Composite thickness, $2 h$, and fibre-volume fraction, $V_{\mathrm{f}}$ are given in Table 2. (Note, each composite is identified by its matrix.) Matrix toughness, evaluated in terms of mode I fracture toughness $\left(G_{\mathrm{Ic}}\right)$ in previous work [25], is also shown in Table 2.

\subsection{Mode II interlaminar fracture testing}

Mode II tests were conducted in accordance with the European Structural Integrity Society (ESIS) procedures for interlaminar fracture-toughness testing [29]. Endnotch flexure (ENF) specimens, which are commonly

Table 2

Composite $2 h$ and $V_{\mathrm{f}}$, and matrix $G_{\mathrm{Ic}}{ }^{\mathrm{a}}$

\begin{tabular}{llll}
\hline Composite & $2 h(\mathrm{~mm})$ & $V_{\mathrm{f}}$ & $\begin{array}{l}\text { Matrix } G_{1 \mathrm{Ic}} \\
\left(\mathrm{kJ} / \mathrm{m}^{2}\right)\end{array}$ \\
\hline $411-45$ & $7.23(0.13)$ & 0.39 & 0.16 \\
8084 & $6.79(0.20)$ & 0.41 & 0.49 \\
9EXL & $7.09(0.25)$ & 0.40 & 1.21 \\
8X33 & $7.16(0.15)$ & 0.39 & 1.35 \\
8S22 & $7.10(0.08)$ & 0.40 & 1.97 \\
\hline
\end{tabular}

${ }^{\mathrm{a}} \pm 1$ S.D. in parentheses. used for high-rate mode-II testing [17], were prepared as shown in Fig. 1. The nominal specimen width $(W)$ was $20 \mathrm{~mm}$, initial crack length $\left(a_{\mathrm{o}}\right) 25 \mathrm{~mm}$ and total specimen length $120 \mathrm{~mm}$. For testing, the specimen was placed in a three-point bending fixture with the halfspan length, $L$, set at $50 \mathrm{~mm}$ and the ratio $a_{\mathrm{o}} / L$ maintained at 0.5 .

The influence of loading rate was investigated by testing the specimens at crosshead displacement rates of 1, 10, 100 and $1000 \mathrm{~mm} / \mathrm{min}$, and $3 \mathrm{~m} / \mathrm{s}$. Tests up to $1000 \mathrm{~mm} / \mathrm{min}$ were conducted on a servo-hydraulic Shimadzu universal testing machine (model EHF-FD1). Load/displacement plots were recorded on an NEC Omniace RT3600 digital data recorder at sampling times of $1 \mathrm{~s}, 100 \mathrm{~ms}, 10 \mathrm{~ms}$ and $1 \mathrm{~ms}$ for $1,10,100$ and $1000 \mathrm{~mm} / \mathrm{min}$, respectively. The $3 \mathrm{~m} / \mathrm{s}$ impact tests were conducted using an instrumented drop-weight impact tester with an optical fibre displacement sensor [31,32], as shown in Fig. 2. A strain gauge attached to a $2.6 \mathrm{~kg}$ falling dart was used to measure load. The optical fibre was fixed on the underside of the specimen, directly below impact point. A laser light source was introduced to the fibre and received by a position-sensitive detector (PSD) which measured the displacement of the fibre during the test. Load and displacement signals were recorded as a function of time at sampling rate of $2 \mu \mathrm{s}$. A $1.5 \mathrm{~mm}$ thick silicone rubber pad was placed on the specimen at the point of impact to reduce signal oscillation [33]. A minimum of three specimens, for each composite, were tested at each rate. The specimens were not precracked.

Expressions for the calculation of mode-II criticalstrain energy-release rate, $G_{\text {IIc }}$, are derived from the Irwin and Kies expression for fracture energy [34]:

$G_{\mathrm{c}}=\frac{P^{2}}{2 W} \frac{\mathrm{d} C}{\mathrm{~d} a}$

where $P$ is load, $C$ compliance (displacement/load; $\delta / P$ ) and $a$ crack length. In this study, $G_{\text {IIc }}$ was calculated using the direct beam theory method [35], which uses

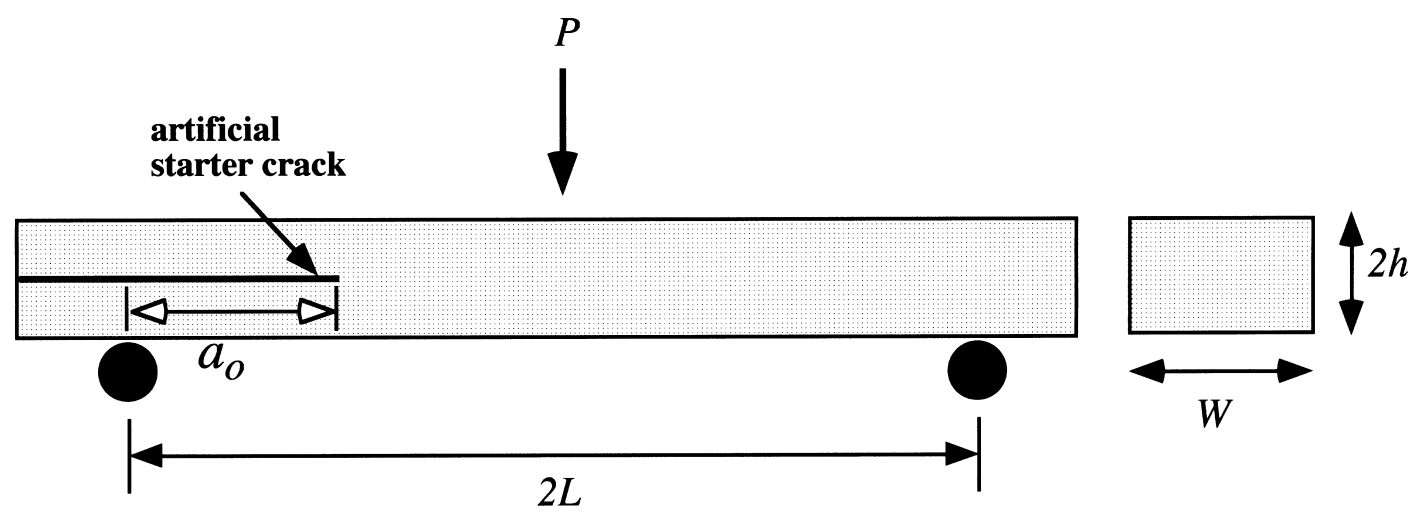

Fig. 1. Mode II end-notch-flexure (ENF) test specimen geometry. 
the ENF compliance expression given by Russell and Street [36]:

$$
C=\frac{2 L^{3}+3 a^{3}}{8 E_{\mathrm{f}} W h^{3}}
$$

where $L$ is the half-span length, $a$ crack length, $E_{\mathrm{f}}$ flexural modulus and $h$ half the specimen thickness. From Eqs. (2) and (3), with $a$ as the sole variable for $C$ :

$G_{\text {IIc }}=\frac{9 a^{2} P^{2}}{16 E W^{2} h^{3}}$

where $P$ is load. For beams under small deflection, an expression for $E$ can be obtained from Eq. (3) which substitutes into Eq. (4), yielding:

$$
G_{\text {IIc }}=\frac{9 a^{2} P \delta}{2 W\left(2 L^{3}+3 a^{3}\right)}
$$

The contribution of kinetic energy $G_{\text {IIke }}$ to composite $G_{\text {IIc }}$ from the $3 \mathrm{~m} / \mathrm{s}$ tests was estimated as follows [15]:

$$
G_{\text {IIke }}=0.078 \rho h \dot{\delta}^{2}
$$

where $\varrho$ is material density and $\dot{\delta}$ crosshead displacement rate. In this study, $G_{\text {IIke }}$ was approximately $0.1 \%$ of $G_{\text {IIc }}$ and hence regarded as negligible.

A $G_{\text {IIc }}$ value for crack initiation $\left(G_{\text {IIc-init }}\right)$ was evaluated using load and displacement data from the nonlinear (NL) point on the load/displacement plot. For $G_{\text {IIc-init }}$, the crack length used in Eq. (5) was the original crack length, $a_{\mathrm{o}}$, of $25 \mathrm{~mm}$. The flexural modulus of each composite, $E_{\mathrm{f}}$, was evaluated from Eq. (3) using the compliance data from the NL point. A $G_{\text {IIc }}$ value for the maximum load point $\left(G_{\text {IIc-max }}\right)$ was also evaluated. Following Jar et al. [37] and assuming $E_{\mathrm{f}}$ is independent of crack length, the change in crack length at the maximum load point, termed effective crack length $\left(a_{\text {eff }}\right)$, was estimated using equation Eq. (3), where $a=a_{\mathrm{eff}}$.

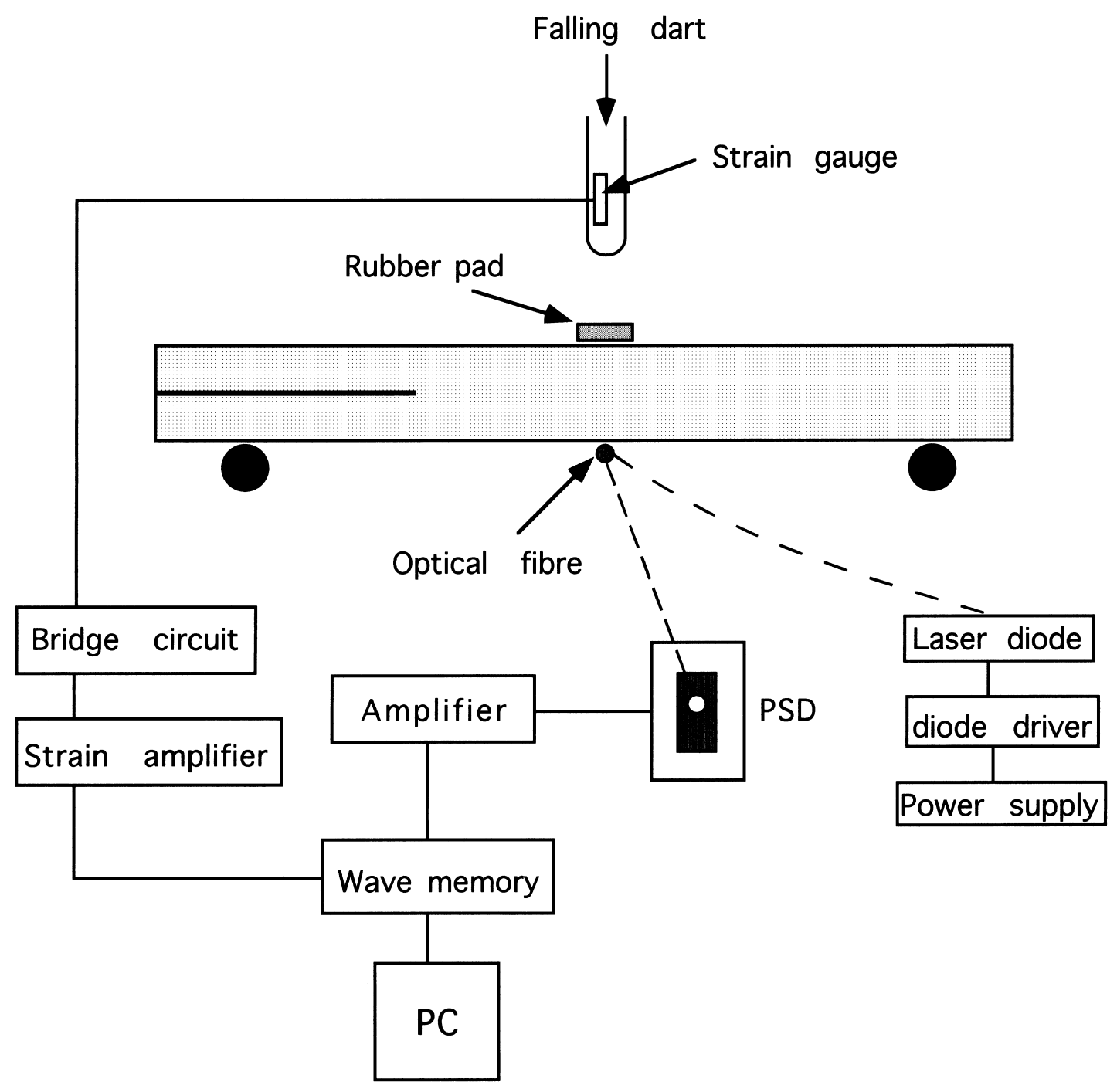

Fig. 2. Apparatus for drop-weight impact testing of ENF specimens at $3 \mathrm{~m} / \mathrm{s}$. 
Then, $a_{\text {eff }}$ was used in Eq. (5) to evaluate $G_{\text {IIc-max }}$. The influence of matrix toughness was assessed by comparing the composite $G_{\text {IIc }}$ results with the order of matrix $G_{\text {Ic }}$. This is consistent with the approach taken in previous mode-II studies [10-14] and is necessary due to the absence of a suitable test method for evaluating bulk matrix $G_{\text {IIc }}$.

It is noted that the ESIS protocol also requires a $G_{\text {IIc }}$ value for a $5 \%$ offset in initial compliance. This value was not obtained for the composites tested in this study as unstable fracture occurred before a $5 \%$ increase in compliance.

\subsection{Microscopy}

Electron microscopy was conducted on a Cambridge S360 scanning electron microscope (SEM). Secondary electron images were obtained from specimens coated with a thin layer of gold. A Zeiss Axioskop I was used to obtain optical micrographs.

\section{Results}

The load/displacement profiles for 411-45 and 8S22 tested at $1 \mathrm{~mm} / \mathrm{min}$, shown in Fig. 3, are similar. A nonlinear (NL) point can be identified and at the maximum load point unstable fracture occurred. This profile is typical for all composites tested up to $1000 \mathrm{~mm} / \mathrm{min}$ on the Shimadzu UTM.

A plot of load and displacement against time from a 3 $\mathrm{m} / \mathrm{s}$ impact test on $8 \mathrm{~S} 22$ is shown in Fig. 4(a). After some initial oscillation, the load signal becomes more linear with increasing time. On the other hand, the
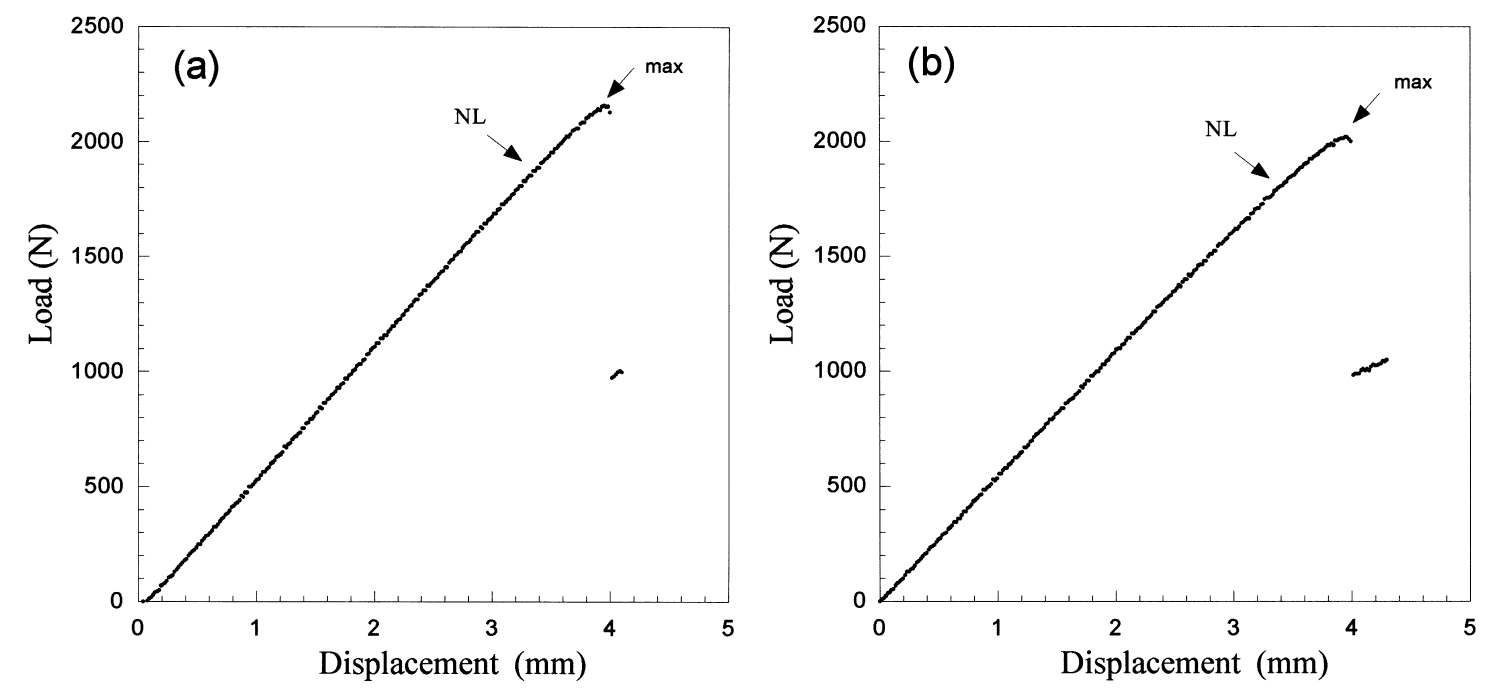

Fig. 3. Load/displacement plot for tests at $1 \mathrm{~mm} / \mathrm{min}$ : (a) 411-45 and (b) $8 \mathrm{~S} 22$.
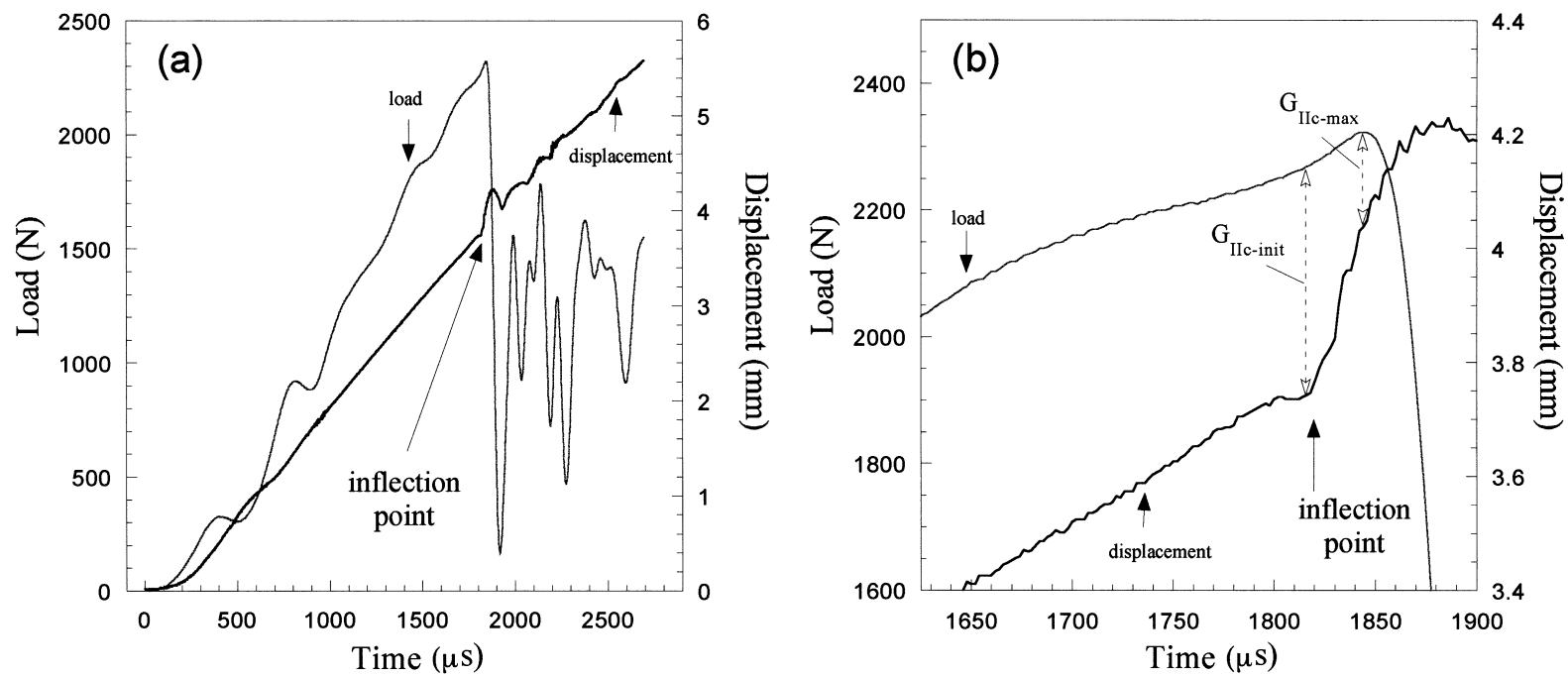

Fig. 4. Test data for $8 \mathrm{~S} 22$ tested at $3 \mathrm{~m} / \mathrm{s}$ (a) load and displacement versus time, (b) as (a) but with inflection and maximum load points magnified. 
displacement signal shows no oscillation. Reasonable linearity indicates a similar loading condition to a static test and validates the use of static equations, such as that in Eq. (5), for $G_{\mathrm{c}}$ evaluation [15,38]. Identification of the fracture initiation point in Fig. 4 (a), to provide raw data for $G_{\text {IIc-init }}$ evaluation, requires interpretation of the displacement signal, which shows a definite upward inflection point before the maximum load point is reached. Kusaka et al. [39] showed that an inflection point in the signal from a strain gauge attached to the surface of a mode-II ENF specimen corresponds to the initiation of crack growth. Todo et al. [32] subsequently showed that the inflection points from a strain gauge and the optical-fibre displacement sensor correspond well. Therefore, for the $3 \mathrm{~m} / \mathrm{s}$ test, the inflection point in Fig. 4 (a) was taken to indicate crack initiation. The inflection and maximum load points are magnified in Fig. 4 (b) and the load and displacement data points used for $G_{\text {IIc-init }}$ and $G_{\text {IIc-max }}$ evaluation are indicated.

The $G_{\text {IIc-init }}$ and $E_{\mathrm{f}}$ results are presented in Fig. 5. The average $G_{\text {IIc-init }}$ values show a slight increase with loading rate, however, when scatter is taken into account, this trend is not so conclusive. The $G_{\text {IIc-max }}$ and $a_{\text {eff }}$ results are presented in Fig. 6, and they show no significant effect of loading rate or matrix toughness.

\section{Discussion}

Although the $G_{\text {IIc-init }}$ results indicate a slight rate effect, this trend may be influenced by the definition of initiation. For tests up to $1000 \mathrm{~mm} / \mathrm{min}$, initiation was defined by the NL point on a load/displacement plot, whereas at 3 $\mathrm{m} / \mathrm{s}$ it was defined by the inflection point on the displacement/time curve. This difference in approach may be responsible for the trend in Fig. 5, especially since $G_{\text {IIc-init }}$ obtained from the $3 \mathrm{~m} / \mathrm{s}$ tests was consistently higher than $G_{\text {IIc-init }}$ from the lower rate tests. Therefore, the following discussion is based only on $G_{\text {IIc-max }}$ results.

\subsection{Effect of loading rate}

The insignificant effect of loading rate on $G_{\text {IIc-max }}$ is consistent with the bulk of previous mode II rate effect studies [17]. Fracture surface micrographs are shown for each composite at the lowest and highest test rates, that is $1 \mathrm{~mm} / \mathrm{min}$ and $3 \mathrm{~m} / \mathrm{s}$, in Figs. 7 and 8 , respectively. Between rates there is no significant difference in matrix deformation and the clean fibre surfaces indicate significant interfacial failure in each composite. These observations support the conclusion of no rate effect. However, it was noted by Cantwell [15] that bridging fibres in unidirectional specimens may hide matrix rate sensitivity. Therefore, further tests with offset fibre plies in the delamination crack plane may be required to confirm the current results.

\subsection{Effect of matrix toughness}

Under mode II loading, sigmoidal-shaped matrix microcracking in the deformation zone ahead of the crack tip is a major energy absorbing mechanism, and these microcracks are responsible for the hackle mark features shown in Figs. 7 and 8. This failure process is more tortuous than in mode I and is the commonly accepted reason for absolute $G_{\text {IIc }}$ to be greater than $G_{\text {Ic }}$. Furthermore, Bradley [40] has suggested that the microcracking provides similar redistribution of load away from the crack tip in both brittle and toughened matrices. Consequently, the increase in composite $G_{\text {IIc }}$ with matrix toughness is not as significant as in mode I. Nevertheless, the bulk of the literature on mode II work shows a matrix effect and given the difference in matrix $G_{\text {Ic }}$ for the current glass-fibre/vinyl ester composites, improved $G_{\text {IIc }}$ in the toughened composites was expected.

Verification of the unexpected trend in $G_{\text {IIc-max }}$ was sought, initially, through examination of matrix deformation on the fracture surfaces. The micrographs in Figs. 7 and 8 show extensive, but similar, matrix hackle mark deformation between composites, which seems to support the conclusion of no matrix effect. However, Hibbs et al. [41], who conducted static mode-II tests on carbon-fibre-reinforced composites with brittle and rubber-toughened epoxy matrices, showed an increase in composite $G_{\text {IIc }}$ with matrix toughness even though all fracture surfaces showed hackle mark deformation. Therefore, the similarity in hackle mark deformation is not sufficient on its own to support the trend in $G_{\text {IIc-max }}$.

In mode I fracture of the bulk matrix, greater $G_{\text {Ic }}$ is related to a greater energy absorbing deformation zone [42]. The previous mode I study on the same glass-fibre/ vinyl ester composites showed greater $G_{\text {Ic }}$ in the composites with the rubber-toughened matrices, as a result of an increase in the matrix-deformation zone size [25]. It is possible that composite $G_{\text {IIc }}$ is also related to the matrix-deformation zone size in the composite. Therefore, to assist explanation of the current $G_{\text {IIc }}$ results, a microscopic examination of the mode-II deformation zone size was made. The 411-45 and 8 S22 composites were used for the examination as they represent the extremes of bulk matrix $G_{\text {Ic }}$. Using specimens tested at 3 $\mathrm{m} / \mathrm{s}$, a thin cross-section was cut from the region between starter crack tip and the point corresponding to $a_{\text {eff }}$. The sections were polished then examined, in transmission mode, in an optical microscope. The micrographs are presented in Fig. 9. The appearance of each image, in terms of brightness and contrast, is different due to the difference in opacity of each matrix. Nevertheless, the crack is clearly visible in the centre of each micrograph, and adjacent to the crack there is a darkened area extending through the resin-rich interlaminar region and into the fibre-dense region. The darkened area corresponds to the deformation zone in 

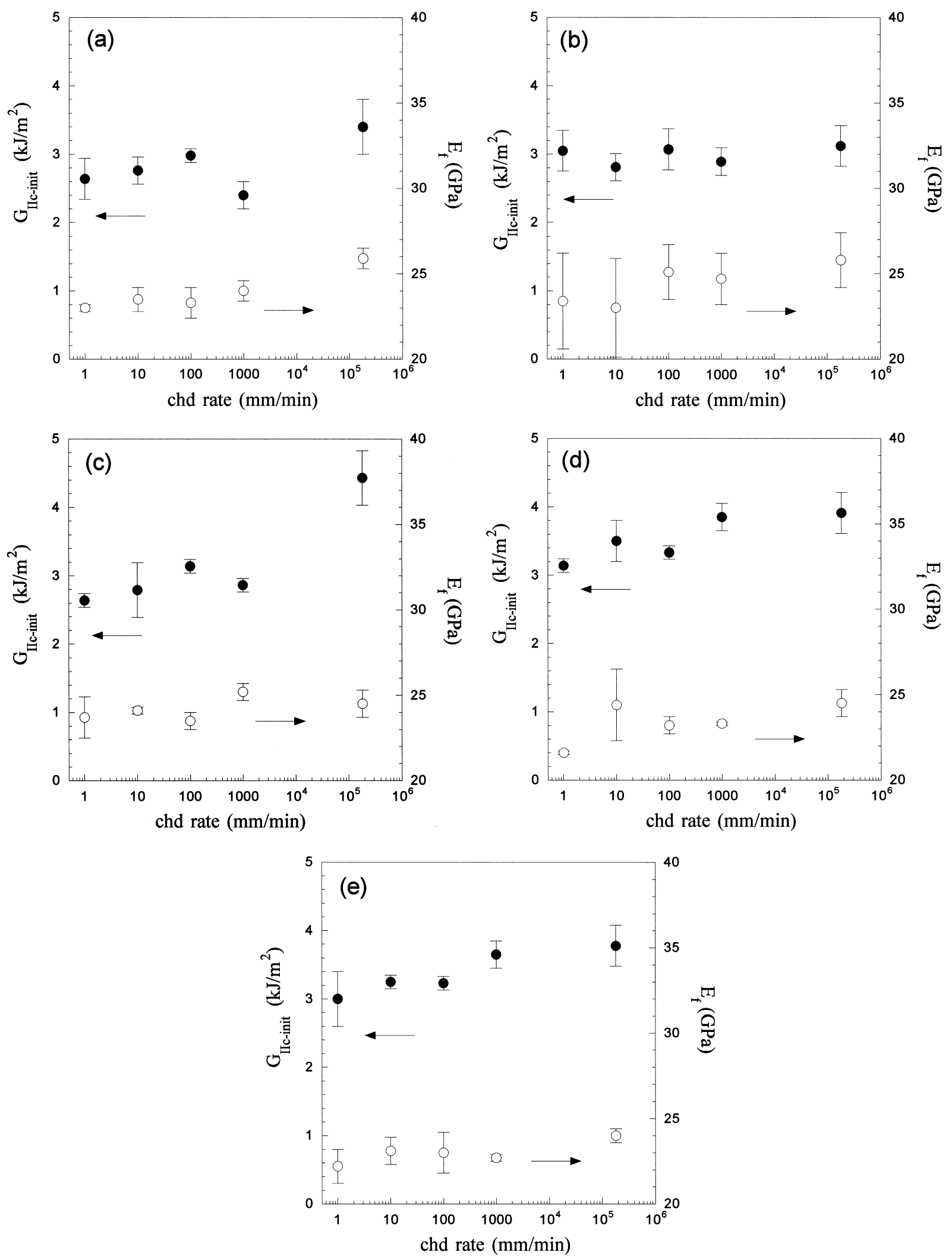

Fig. 5. $G_{\text {IIC-init }}$ (closed symbols) and $E_{\mathrm{f}}$ (open symbols) versus crosshead displacement (chd) rate; (a) 411-45, (b) 8084, (c) 9EXL, (d) 8X33, and (e) 8 S22 (error bars signify \pm 1 S.D). 

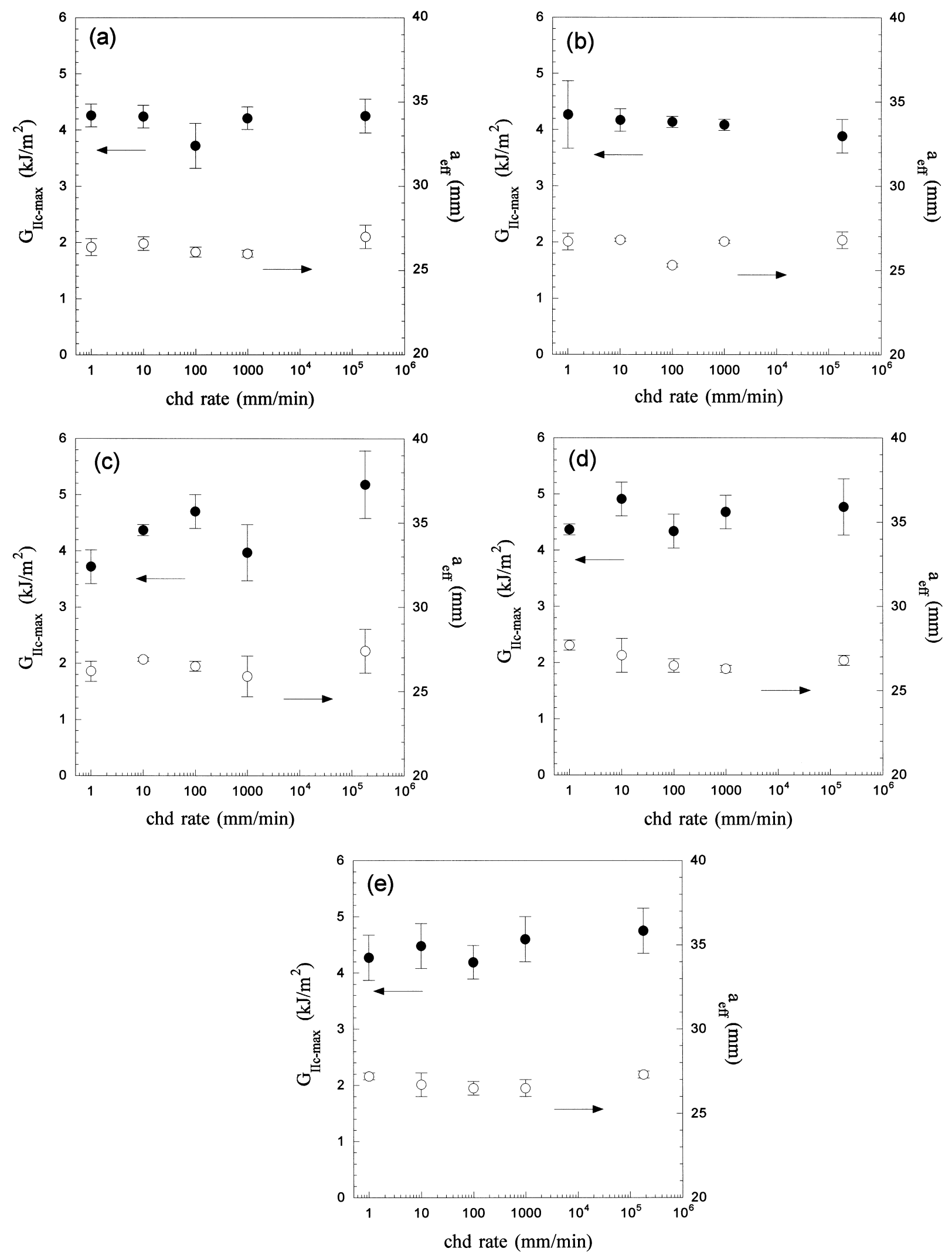

Fig. 6. $G_{\text {IIc-max }}$ (closed symbols) and $a_{\text {eff }}$ (open symbols) versus crosshead displacement (chd) rate; (a) 411-45, (b) 8084, (c) 9EXL, (d) 8X33, and (e) $8 \mathrm{~S} 22$ (error bars signify \pm 1 S.D.). 
the matrix which developed during initial loading of the specimen and subsequent crack growth between the initiation and maximum load points. In each composite, there is no significant difference in the depth of this zone. This observation supports the conclusion, drawn from the experimental results, that there is no effect of matrix toughness. The same conclusion was made when the thin sections were examined under polarised light.

However, an explanation for the insignificant matrix effect is still required. Todo et al. [43] modelled mode II failure from an artificial starter crack, using experimental data from similar glass-fibre/vinyl-ester specimens, and reported crack initiation in the direction of the fibre/ matrix interface. In addition, in-situ observation of
mode-II failure in carbon-fibre composites by Friedrich et al. [11] and Bradley [40] showed that the growth of the microcracks ahead of the crack tip, which are responsible for the hackle-mark formation, are likely to be impinged by the fibre-dense regions either side of the interlaminar region. Fig. 9. has already indicated that the matrix-deformation zone in these glass-fibre/vinylester composites systems extends into the fibre-dense regions. It is suggested therefore that the mode-II failure in these composites is controlled by the interface. That is, after crack initiation towards the interface, stress concentrations at the interface were sufficient to cause fibre-matrix debonding. This subsequently caused unstable crack growth from the same point (i.e. $\left.a_{\mathrm{eff}}\right)$ in
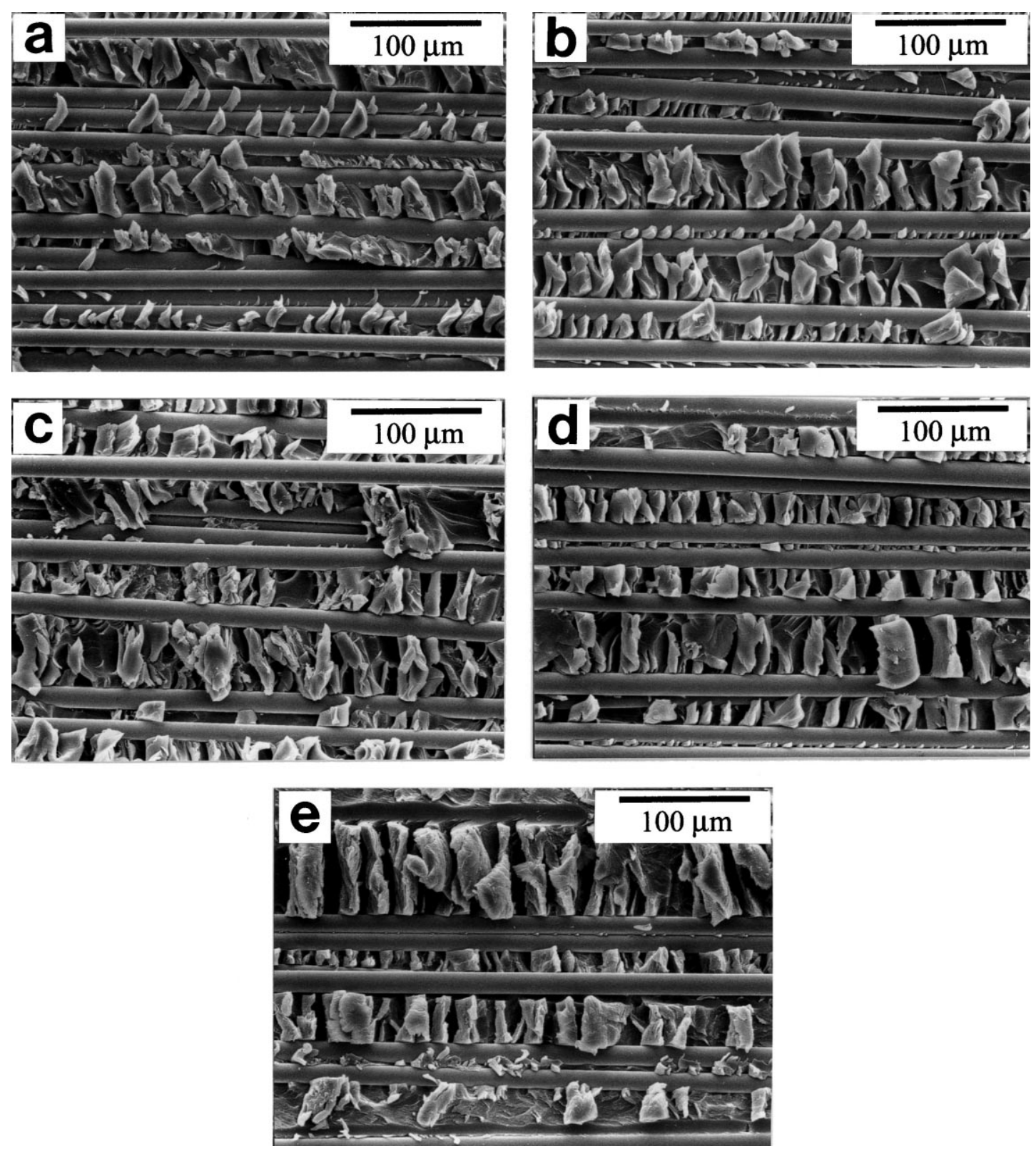

Fig. 7. Fracture surfaces of mode II ENF specimens tested at $1 \mathrm{~mm} / \mathrm{min}$; (a) 411-45, (b) 8084, (c) 9EXL, (d) 8X33, and (e) 8S22. Crack growth from left to right. 
each composite, before any significant increase in $G_{\mathrm{IIc}}$ as a result of increased matrix toughness became apparent. The conclusion that the interface in glass-fibre composites has a dominant role in the failure process is consistent with previous work by Todo et al. [6]. Furthermore, all the matrices are vinyl ester-based and the interface-bond strength is likely to be similar, hence interface-controlled failure is likely to produce a similar result in each composite.

It is noted that similar mode-II work on glass-fibre composites indicated a loading rate and a matrix effect [14]. However, the variation in matrix toughness was achieved through the use of different thermoset matrices (polyester, vinyl ester and epoxy) and since the fibre was the same in these composites, the interface-bond strength would also vary. Therefore, direct comparison with the current results may not be appropriate.

\subsection{Influence of specimen thickness}

Previous mode-II studies have reported an increase in $G_{\text {IIc }}$ with specimen thickness [15,44]. Davies [45] has subsequently shown that friction between crack faces is significant in thicker specimens, and when a folded PTFE separator film is placed between the crack faces of a $5 \mathrm{~mm}$ thick carbon-fibre/PEEK specimen, $G_{\text {IIc }}$ is reduced to the value obtained from $3 \mathrm{~mm}$ thick specimens. Furthermore, Carlsson et al. [46] showed error in
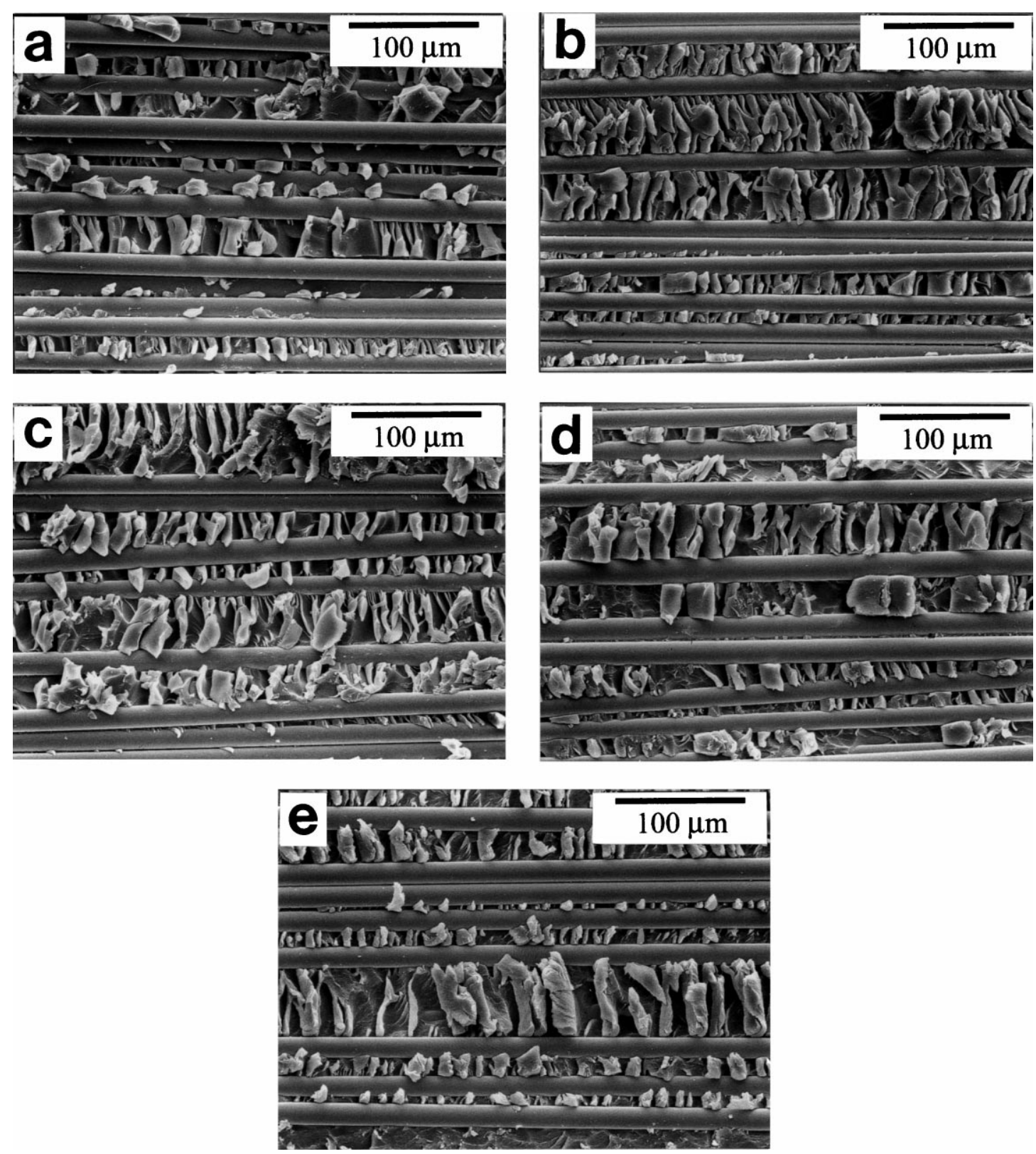

Fig. 8. Fracture surfaces of mode II ENF specimens tested at $3 \mathrm{~m} / \mathrm{s}$; (a) 411-45, (b) 8084, (c) 9EXL, (d) 8X33, and (e) 8S22. Crack growth from left to right. 

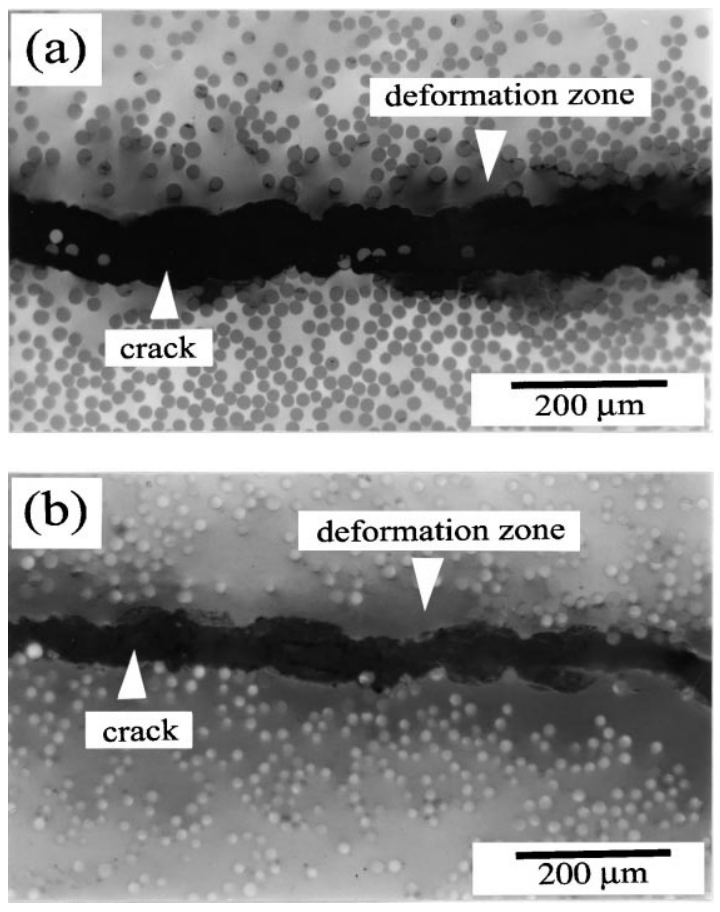

Fig. 9. Thin cross-sections of mode II ENF specimens, tested at $3 \mathrm{~m} / \mathrm{s}$, showing deformation zone depth in (a) 411-45 and (b) 8S22. Crack growth in the $z$ direction.

$G_{\text {IIc }}$ of only $2-4 \%$ for thin $(<2 \mathrm{~mm}$ ) ENF specimens. It is possible, therefore, that the results in Figs. 5 and 6 were influenced by specimen thickness or friction. Further investigation was made with specimens cut from the original $7 \mathrm{~mm}$ thick laminates, milled to a thickness of $4.5 \mathrm{~mm}$ and tested at $1 \mathrm{~mm} / \mathrm{min}$.

The $G_{\text {IIc-max }}$ results in Fig. 10 show no influence of specimen thickness. There is also no influence of matrix toughness which confirms the original results. The good agreement in $G_{I I c-m a x}$ between thick and thin specimens suggests no significant friction in the thicker specimens. Where the artificial starter crack is either an Al or polymer film (other than PTFE), Davies [45] suggested that a PTFE separator should be placed between the crack faces. The results for $G_{\text {IIc-max }}$ presented here suggest that the PTFE separator is not necessary for the systems studied here.

\subsection{Future work}

As the results presented in this paper show no matrix effect, a number of directions for future work are proposed. Primarily, it would be interesting to determine if, resulting from improved bond strength, there is greater utilisation of matrix toughness under mode-II loading in the composites with the rubber-modified vinyl ester. Other work could be based on interlaminar fracture-toughness testing. New configurations for the composite mode-II test are under investigation [47]. They include the fourpoint ENF (4ENF) and stabilised end-notch-flexure

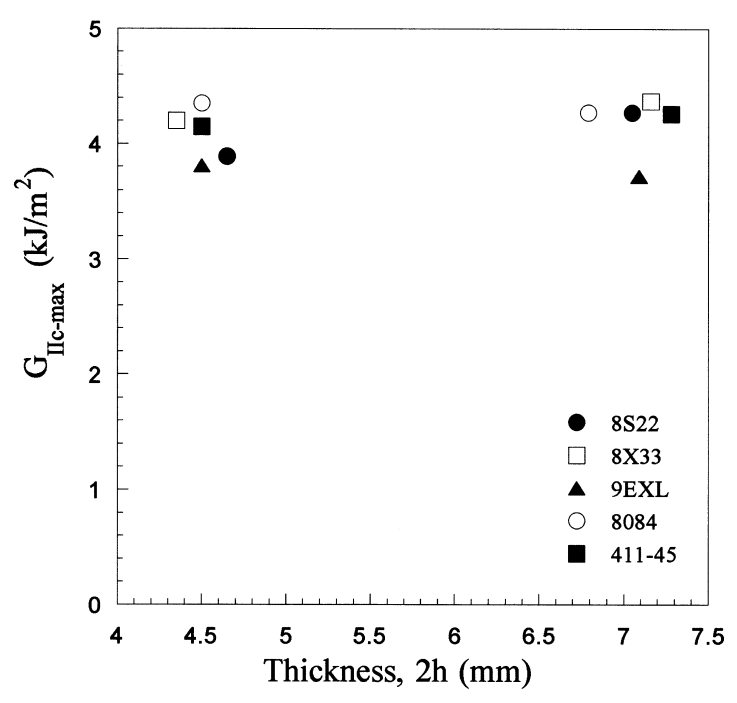

Fig. 10. $G_{\text {IIc-max }}$ versus specimen thickness $(2 h)$.

(SENF) specimens, which promote stable crack growth. These configurations could be utilised to determine if the elimination of unstable crack growth caused by the ENF test enhances the sensitivity of composite $G_{\text {IIc }}$ to variations in bulk matrix toughness. Mixed-mode testing (I/II) could also be undertaken. It is believed that tougher matrices improve resistance to impact induced delamination in composite structures $[1,17]$. However, the loading conditions under impact are complex [3] and through-thickness damage is likely to result from mixedmode loading. This has provided the motivation for previous mixed-mode (I/II) studies [13]. Although the $G_{\text {IIc }}$ results in this paper show no matrix effect, the significant improvement in composite $G_{\text {Ic }}$ shown in previous work $[25,26]$ may lead to improved results for mixed-mode interlaminar fracture toughness $G_{\mathrm{I} / \mathrm{IIc}}$, and hence, impact-induced delamination resistance. For the same reason, the influence of matrix toughness on energy absorption and delamination damage area in plate structures should also be studied.

\section{Conclusions}

The influence of loading rate and matrix toughness on the mode-II interlaminar fracture toughness has been investigated in glass-fibre-reinforced composites with brittle and rubber toughened vinyl-ester matrices. Endnotch-flexure specimens were tested at crosshead displacement rates ranging from $1 \mathrm{~mm} / \mathrm{min}$ to $3 \mathrm{~m} / \mathrm{s}$.

Composite $G_{\text {IIc }}$ at the maximum load point was compared with the order of matrix $G_{\text {Ic }}$, and showed no significant effect of loading rate or matrix toughness. Microscopic examination of fracture surfaces and deformation-zone depth shows similar deformation features in each composite which do not vary over the 
range of test rates studied. These observations support the mechanical test results. The absence of a clear loading rate effect is consistent with bulk of published modeII work, but the absence of a clear matrix effect is not. It is suggested that failure in these glass-fibre/vinyl-ester composites is interface controlled, with unstable failure initiated before an increase in composite $G_{\text {IIc }}$ as a result of increased matrix toughness becomes apparent.

The results suggest that the use of rubber-toughened vinyl-ester matrices in glass-fibre composites will not improve resistance to mode-II dominated impactinduced delamination. However, through-thickness damage in an impacted composite structure is likely to involve mixed-mode loading. It is proposed, therefore, that further work is undertaken to study the matrix effect on stabilised mode-II interlaminar fracture toughness, mixed-mode (I/II) interlaminar fracture toughness, and on delamination resistance in plate structures subjected to transverse impact loading.

\section{Acknowledgements}

This study was supported financially by the Australian Research Council (Large Grant scheme) and the Australian Federal Government's Department of Education, Training and Youth Affairs (Targeted Institutional Links program). The core-shell toughened resin (9EXL) was supplied by the Co-operative Research Centre (CRC) for Polymers in Australia. The assistance of staff and use of resources in the Electron Microscope Unit at ANU is acknowledged. The technical assistance of Mr. D. Krivanek in the Department of Engineering, ANU, and Dr. M. Todo, Dr. T. Kuboki and Mr. T. Mada at RIAM, Kyushu University, is also gratefully acknowledged.

\section{References}

[1] Richarson MOW, Wiseheart MJ. Review of low-velocity impact properties of composite materials. Composites 1996;27A:112331.

[2] Cantwell WJ, Morton J. The impact resistance of composite materials - a review. Composites 1991;52(5):347-62.

[3] Garg AC. Delamination - a damage mode in composites. Eng Fract Mech 1988;29(5):557-84.

[4] Davies GAO, Hitchings D, Zhou G. Impact damage and residual strengths of woven fabric glass/polyester laminates. Composites 1996;27A:1147-56.

[5] Mahinfalah M, Skordahl RA. The effects of hail damage on the fatigue strength of a graphite/epoxy composite laminate. Comp Struc 1998;42:101-6.

[6] Wang H, Vu-Khanh T. Fracture mechanics and mechanisms of impact-indiced delamination in composites. J Comp Mater 1995;29(2):156-78.

[7] Wu E, Wang J. Behaviour of stitched laminates under in-plane and tensile transverse impact loading. J Comp Mater 1995;27(17):2254-79.
[8] Bibo GA, Hogg PJ. Influence of reinforcement architecture on damage mechanisms and residual strength of glass/epoxy composite systems. Comp Sci Technol 1998;58:803-13.

[9] Dransfield K, Baillie C, Mai Y-W. Improving the delamination resistance of CFRP by stitching - a review. Comp Sci Technol 1994;50:305-17.

[10] Smiley AJ, Pipes RB. Rate sensitivity of mode II interlaminar fracture toughness in graphite/epoxy and graphite/PEEK composite materials. Comp Sci Technol 1987;29:1-15.

[11] Friedrich K, Walter R, Carlsson LA, Smiley AJ, Gillespie JW. Mechanisms for rate effects on interlaminar fracture toughness of carbon/epoxy and carbon/PEEK composites. J Mater Sci 1989;24:3387-98.

[12] Maikuma H, Gillespie JW, Wilkins DJ. Mode II interlaminar fracture of the center notch flexural specimen under impact loading. J Comp Mater 1990;24:124-49.

[13] Blackman BRK, Dear JP, Kinloch AJ, Macgillivray H, Wang Y, Williams JG, Yayla P. The failure of fibre composites and adhesively bonded fibre composites under high rates of test, Part III. Mixed-mode I/II and mode II loadings. J Mater Sci 1996;31:4467-77.

[14] Compston P, Jar P-YB, Davies P. Matrix effect on the static and dynamic interlaminar fracture toughness of glass-fibre marine composites. Composites 1998;29B(4):505-16.

[15] Cantwell WJ. The influence of loading rate on the mode II interlaminar fracture toughness of composite materials. J Comp Mater 1997;31(4):1364-80.

[16] Todo M, Nakamura T, Takahashi K. Mode II interlaminar fracture behaviour of fiber reinforced polyamide composites under static and dynamic loading conditions. In: Proceedings of Thirteenth Annual Technical Conference on Composite Materials. Baltimore (MD). American Society for Composites, 1998. p. 643-4.

[17] Cantwell WJ, Blyton M. Influence of loading rate on the interlaminar fracture properties of high performance composites - a review. Appl Mech Rev 1999;52(6):199-212.

[18] Davies P. Application of composites in a marine environmen: status and problems. In: Cardon AH, editor. Durability analysis of structural composite systems. Rotterdam: A.A. Balkema, 1996.

[19] Davies P, Lemoine L, editors. Nautical construction with composite materials. In: Proceedings of the 3rd IFREMER Conference, Paris, 1992.

[20] Shenoi RA, Wellicome JF, editors. Composite Materials in Marine Structures. Cambridge: Cambridge Ocean Technology Press, 1993.

[21] Dow Plastics. Derakane epoxy vinyl ester resins, technical product information.

[22] Guiterrez J, Le Ley F, Hoarau P. A study of the aging of glass fibre resin composites in a marine environment. In: Nautical construction with composite materials. Proceedings of the 3rd IFREMER Conference, Paris, 1992. p. 338.

[23] Pham S, Burchill PJ. Toughening of vinyl ester resins with modified polybutadienes. Polymer 1995;36:3279-85.

[24] Siebert AR, Guiley CD, Kinloch AJ, Fernando M, Heijnsbrock EPL. Elastomer-modified vinyl ester resins: impact and fatigue resistance. In: Riew CK, Kinloch AJ, editors. Toughened plastics II: novel approaches in science and engineering. American Chemical Society, 1987.

[25] Compston P, Jar P-YB, Burchill PJ, Takahashi K. The transfer of matrix toughness to composite mode I interlaminar fracture toughness in glass-fibre/vinyl ester composites. App Comp Mater, submitted for publication.

[26] Compston P, Jar P-YB, Burchill PJ, Takahashi K. The effect of matrix toughness and loading rate on the mode I interlaminar fracture toughness of glass-fibre/vinyl ester composites. ESIS STP, submitted for publication. 
[27] Burchill PJ, Simpson GJ. Improved interlaminar fracture toughness for vinyl ester resin-fibre glass composites. In: Proceedings of Eleventh International Conference on Composite Materials (ICCM-11), vol. II. Cambridge (UK): Woodhead Publishing Ltd, 1997. p. 254.

[28] Material synthesised by PJ Burchill according to informatoin provided by BF Goodrich.

[29] Protocols for interlaminar fracture testing of composites. 1993. Delft (The Netherlands): European Structural Integrity Society (ESIS), 1993.

[30] Hull D. An introduction to composite materials. Cambridge: Cambridge University Press, 1981.

[31] Beguelin Ph. Approche experimentale du comportement mecanique des polymeres en sollicitation rapide. $\mathrm{PhD}$ thesis, Ecole Polytechnique Federale de Lausanne (EPFL), Switzerland, 1996 (in French).

[32] Todo M, Nakamura T, Mada T, Takahashi K. Measurement of dynamic interlaminar fracture toughness of FRP laminates using dynamic displacement measuring apparatus. Adv Comp Mater 1998;7(3):285-97.

[33] Aggag G, Takahashi K. Study of oscillation signals in instrumented charpy impact testing. Polymer Eng Sci 1996;36(17):2260-6.

[34] Irwin GR, Kies JA. Critical energy rate analysis of fracture strength. J Welding 1954;19:193.

[35] Carlsson LA, Gillespie JW. Mode-Iinterlaminar fracture of composites. In: Friedrich K, editor, Application of fracture mechannics to composites. Amsterdam: Elsevier, 1989.

[36] Russell AJ, Street KN. Factors affecting the interlaminar fracture energy of grpahite/epoxy laminates. In: Proceedings of the Fourth International Conference on Composite Materials (ICCM-IV), Tokyo, Japan, 1982.

[37] Jar P-YB, Mulone R, Davies P, Kausch HH. A study of the effect of forming on the mechanical behaviour of carbon-fibre/PEEK composites. Comp Sci Technol 1993;46:7-19.

[38] Beguelin Ph, Kausch HH. A technique for studying the fracture of polymers from low to high loading rates. In: Williams JG, Pavan A, editors, Impact and dynamic fratcure of polymers and composites, ESIS 19. London: Mechanical Engineering Publications, 1995.

[39] Kusaka T, Kurokawa K, Hojo M, Ochiai S. Estimation of interlaminar fracture toughness of CFRP laminates by measuring the surface strain of specimen. Proceedings of JSMS Composites 1996;26:203-4.

[40] Bradley W. Relationship of matrix toughness to interlaminar fracture toughness. In: Friedrich K, editor. Application of fracture mechanics to composites. Amsterdam: Elsevier, 1989.

[41] Hibbs MF, Tse MK, Bradley WL. Interlaminar fracture toughness and real-time fracture mechansims of some toughened graphite/epoxy composites. In: Johnston NJ, editor. Toughened Composites ASTM STP 937. Philadelphia (PA): American Society for Testing and Materials, 1987.

[42] Broek D. Elementary engineering fracture mechanics, 4th ed. Dortrecht (The Netherlands): Martinus Nijhoff Publishers, 1986.

[43] Todo M, Jar PY-B, Takahashi K. Initiation of the mode II interlaminar crack growth from insert film in end-notch-flexure specimens. Comp Sci Technol 2000;60:263-72.

[44] Davies P, Kausch HH, Williams JG. Round robin interlaminar fracture testing of carbon-fibre reinforced epoxy and PEEK composites. Comp Sci Technol 1992;43:129-36.

[45] Davies P. Influence of ENF specimen geometry and friction on the mode II delamination resistance of carbon/PEEK. J Thermoplastic Comp Mater 1997;10:353-61.

[46] Carlsson LA, Gillespie JW, Pipes RB. On the analysis and design of the end-notch-flexure (ENF) specimen for mode II testing. J Comp Mater 1986;20:594-604.

[47] Davies P, Sims GD, Blackman BRK, Brunner AJ, Kageyama K, Hojo $\mathrm{M}$, et al. Comparison of test configurations for the determination of $G_{\text {IIc }}$ : an international round robin. In: Proceedings of the Fourth European Conference on Composites: Testing and Standardisation. London (UK): IOM Communications Ltd, 1998. p. $180-9$. 